\title{
PERTEMPURAN IDEOLOGI DESAINER GRAFIS MODERNISME DAN POSTMODERNISME DALAM KONTEKS FONT HELVETICA
}

\author{
Irwan Harnoko \\ Jurusan Desain Komunikasi Visual, School of Design, BINUS University \\ Jln. KH. Syahdan No. 9, Palmerah, Jakarta Barat 11480 \\ irwanonni@yahoo.com
}

\begin{abstract}
This article discusses the mindset of modernism designers: Massimo Vignelli, Wim Crouwel as opposed to the perspective of postmodernism designers: Paula Scher and David Carson on Helvetica font. This discussion becomes interesting because the leaders of the two sides are the key figures in the world of graphic design. Their opinions on Helvetica font can be used as a guide to study world's graphic design, due to they dominate the mindset of contemporary designers.
\end{abstract}

Keywords: Helvetica, modernism, postmodernism

\begin{abstract}
ABSTRAK
Artikel ini membahas tentang pola pikir desainer modernisme: Massimo Vignelli, Wim Crouwel yang bertolak belakang dengan cara pandang desainer postmodernisme: Paula Scher dan David Carson terhadap font Helvetica. Pembahasan ini menarik karena tokoh dari kedua kubu tersebut adalah tokoh penting dalam dunia desain grafis. Pendapat mereka mengenai font Helvetica tersebut dapat digunakan sebagai pedoman untuk mempelajari karya desain grafis dunia, karena dua kubu tersebut hingga saat ini sangat mendominasi pola pikir desainer masa kini.
\end{abstract}

Kata kunci: Helvetica, modernisme, postmodernisme 


\section{PENDAHULUAN}

Font Helvetica kembali menjadi pembicaraan hangat, ketika sutradara Gary Huswit yang sekaligus produser membuat film "hanya" tentang sebuah jenis huruf, Helvetica. Film berdurasi 1 jam 20 menit ini dibuat untuk memperingati 50 tahun kelahiran Helvetica. Sang sutradara membuat film ini berdasarkan rasa heran Hustwit, alasan sebuah huruf demikian populer digunakan, walaupun sudah berusia setengah abad.
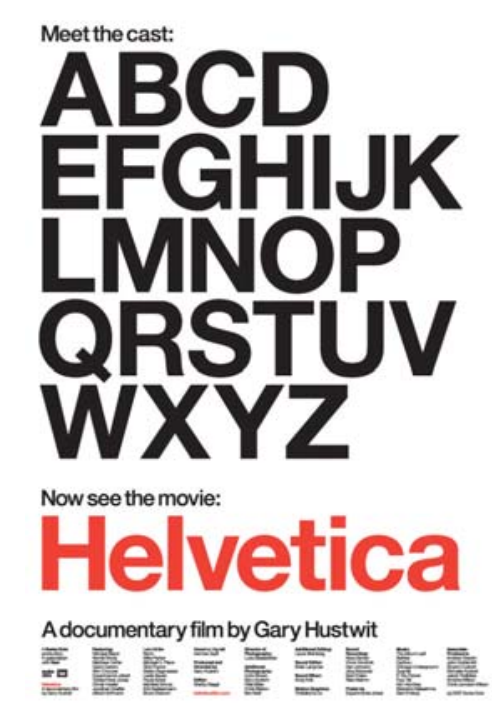

Gambar 1 Cover DVD Helvetica

Sumber: http://www.creativeworld.com.au/blog/wpcontent/uploads/2007/08/helveticamovie.jpg)

Penulisan ini membahas kepopularan jenis huruf Helvetica yang sudah berusia setengah abad, namun jenis font ini masih terus-menerus digunakan untuk berbagai keperluan di seluruh belahan dunia. Mulai dari sign system arsitektural, rambu jalan raya, hingga logoype, dan banyak lagi.

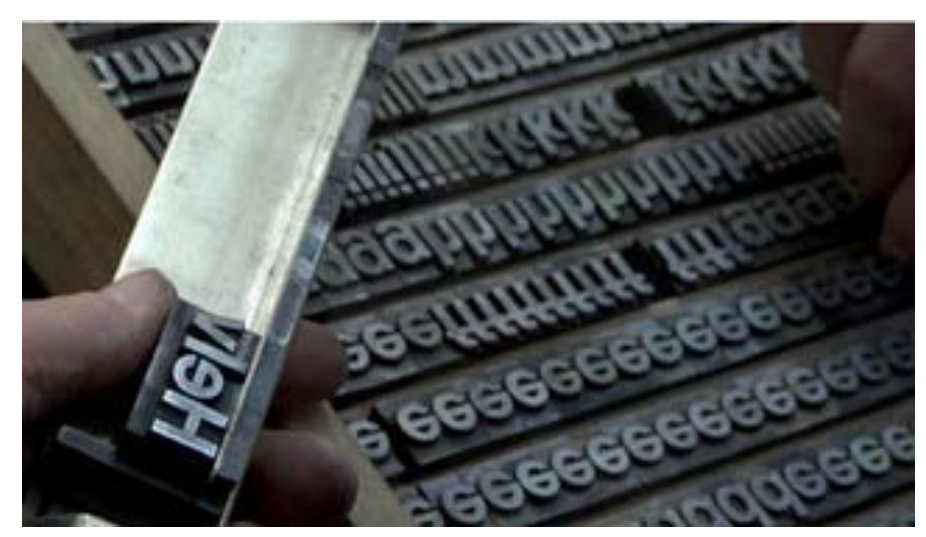

Gambar 2 the Metal Type Helvetica

(Sumber: http://www.helveticafilm.com/images/highres/manfred.jpgl) 


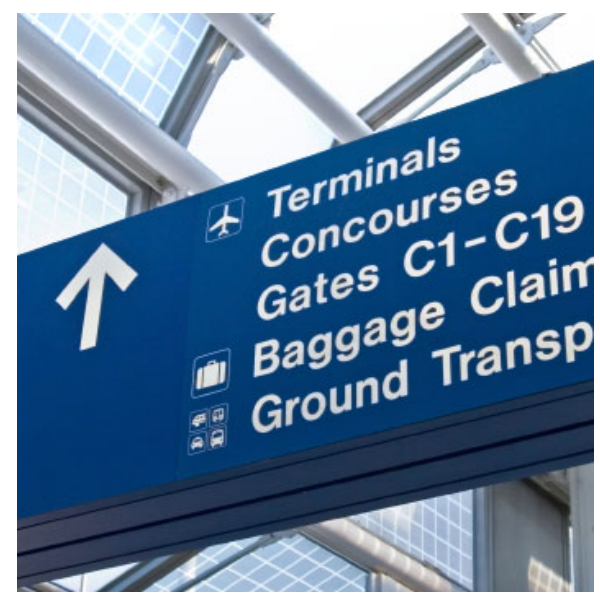

Gambar 3 Sign system - Helvetica

(Sumber: http://periscopedepth.files.wordpress.com/2009/10/

helvetica.jpg?w=296\&h=300)

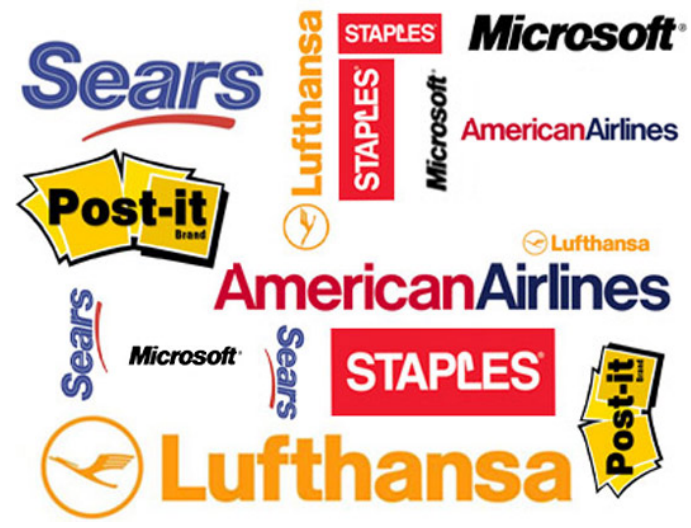

Gambar 4 Logo - Helvetica

(Sumber: http://blogs.ubc.ca/laurawang/files/2011/03/helvetica3_070607_ssh1.jpg)

Beragam pandangan dari beberapa tokoh desainer grafis dunia mengenai jenis huruf Helvetica ini seperti: Massimo Vignelli (New York), Wim Crouwel (Amsterdam), Michael Bierut (New York), Paula Scher (New York), David Carson (Portland), Erik Spiekermann (Berlin). Pendapat mereka terbagi dua antara desainer yang menggemari dan tidak terhadap Helvetica.

\section{METODE PENELITIAN}

Penelitian ini menggunakan jenis penelitian kualitatif. Hal ini disebabkan pendekatan dengan model kualitatif memberikan rincian yang lebih kompleks tentang fenomena yang sulit diungkapkan oleh metode kuantitatif. Teknik pengumpulan data dilakukan dengan kepustakaan dan obeservasi dari buku-buku, internet dan video dokumenter. Selain itu, penulis menghubungkan antara pemikiran filsuf modernisme dan postmodernisme dengan praktisi desain dunia yang beraliran modernisme dan postmodernisme dalam konteks font Helvetica. 


\section{HASIL DAN PEMBAHASAN}

Ideologi adalah sistem kepercayaan (belief system) yang dianut karakteristik kelas atau kelompok masyarakat tertentu. Pengertian ini dapat menjadi salah satu kunci jawaban alasan terjadinya jurang pemisah antara kelompok desainer grafis yang menyukai Helvetica dan kelompok yang tidak menyukainya. Dalam film Helvetica yang dibuat oleh Gary Huswit, seorang desainer legendaris Massimo Vignelli (2007) mengatakan:

"You can say, "I love you," in Helvetica. And you can say it with Helvetica Extra Light if you want to be really fancy. Or you can say it with the Extra Bold if it's really intensive and passionate, you know, and it might work."

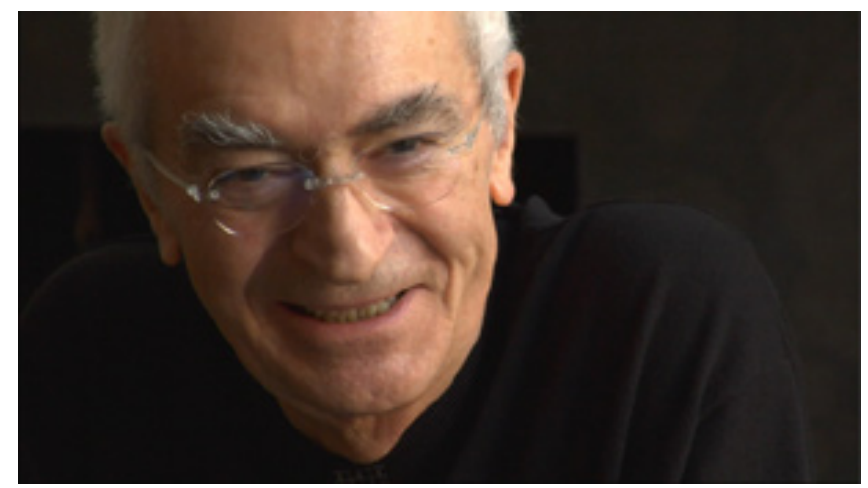

Gambar 5 Massimo Vignelli dalam wawancara video documenter Helvetica

(Sumber: http://4.bp.blogspot.com/_E6R2cPv2zc/UMqC3HrbWFI/ AAAAAAAAAOo/2KFWoj2focQ/s1600/l.jpg)

Pernyataan Massimo Vignelli tersebut jelas menguatkan bahwa ia termasuk desainer grafis yang mempunyai ideologi modernisme karena berpaham totaliter. Berikut ini adalah beberapa karya besar dari desainer Massimo Vignelli.

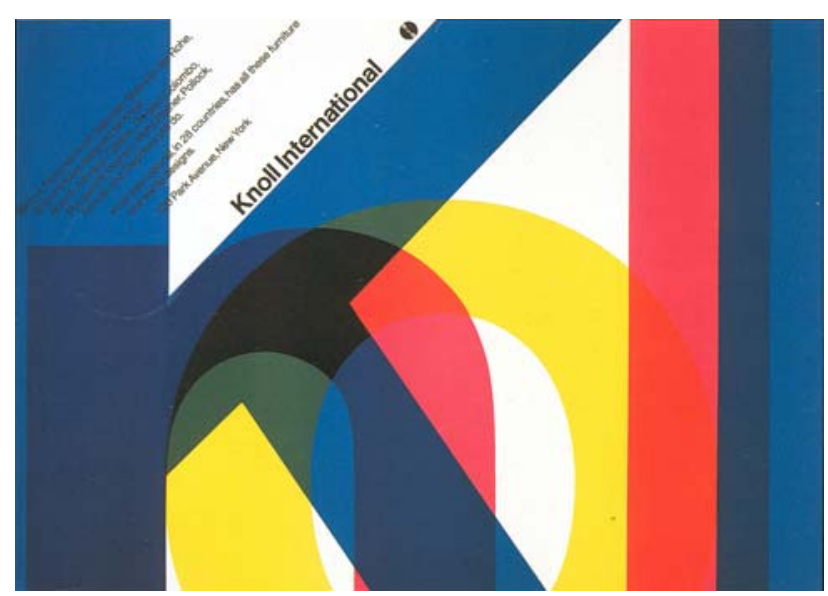

Gambar 6 Knoll - Massimo Vignelli

(Sumber: http://4.bp.blogspot.com/-_E6R2cPv2zc/UMqC3HrbWFI /AAAAAAAAAOo/2KFWoj2focQ/s1600/l.jpg) 


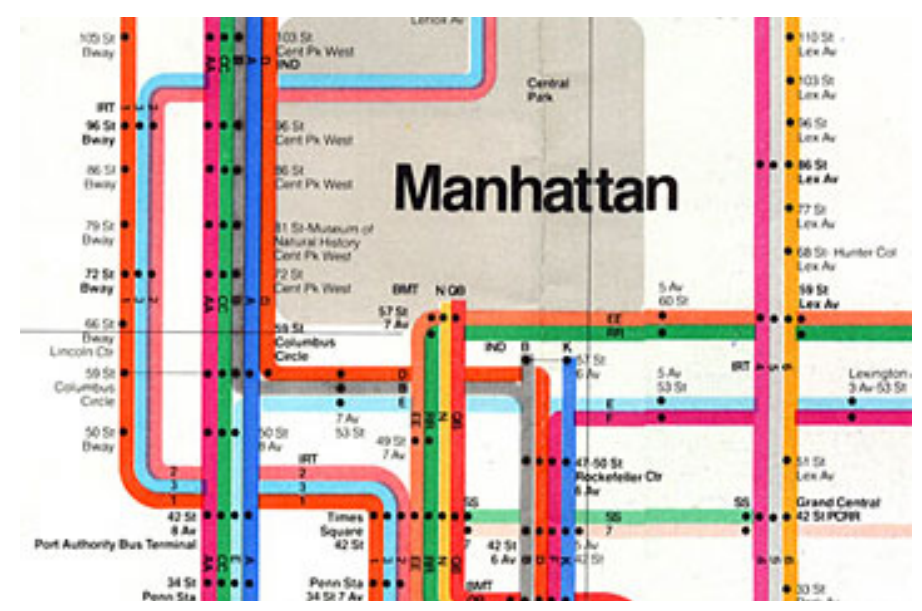

Gambar 7 Peta Subway Manhattan - Massimo Vignelli (Sumber: http://37signals.com/svn/images/subwaysmall.jpg)

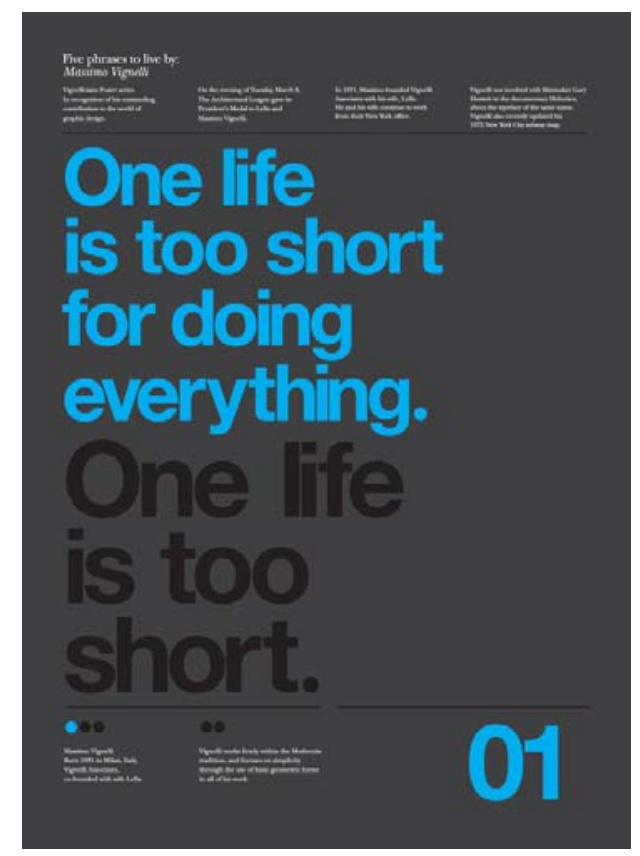

Gambar 8 Poster - Massimo Vignelli

(Sumber: http://1.bp.blogspot.com/-oHRZzOz6MHk/TrHxR13d6I/AAAAAAAAAKg/cfJh3iyCkE/s1600/MassimoVignelliDesign2.jpg)

Hal senada dilontarkan oleh Wim Crouwel seorang desainer Grafis legendaris asal Amsterdam. Banyak orang menjuluki Crouwel dengan nama Gridnik. Karena seluruh desainnya tidak lepas dari Grid (Grid adalah susunan kerangka yang dibangun atas garis dengan posisi vertikal dan horizontal, grid dipergunakan sebagai alat bantu untuk menyusun atau mengatur objek dalam kontek perencanaan dalam ruang gambar dua dimensi). Dalam video dokumenter Helvetica. Wim Crouwel (2007) mengatakan: "The meaning is in the content of the text and not in the typeface, and that is why we loved Helvetica very much.” 


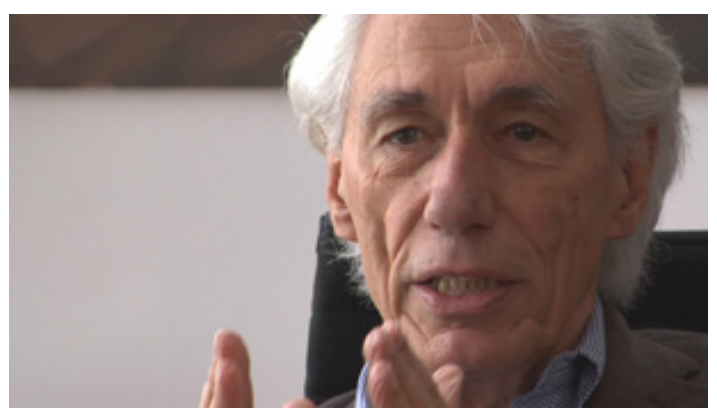

Gambar 8 Wim Crouwel

(Sumber: http://www.helveticafilm.com/images/sm.crouwel1.jpg)

Pernyataan Crouwel ini dengan jernih menyatakan bahwa karena Helvetica adalah font yang sangat netral tidak berekspresi jadi dapat digunakan untuk apapun, karena arti dari teks bukan dari bentuk hurufnya. Jadi, Helvetica dapat digunakan untuk apapun sangat universal tidak mengandung muatan sejarah dan etnis kedaerahan tertentu. Sehingga huruf ini abadi seperti halnya ilmu pengetahuan (science) yang tidak memedulikan sejarah. Oleh karena itu, tidaklah mengherankan Crouwel mencintai sekali sistim Grid karena semuanya sangat terukur dan rasional seperti halnya science. Berikut ini adalah beberapa karya besar dari desainer Wim Crouwel.
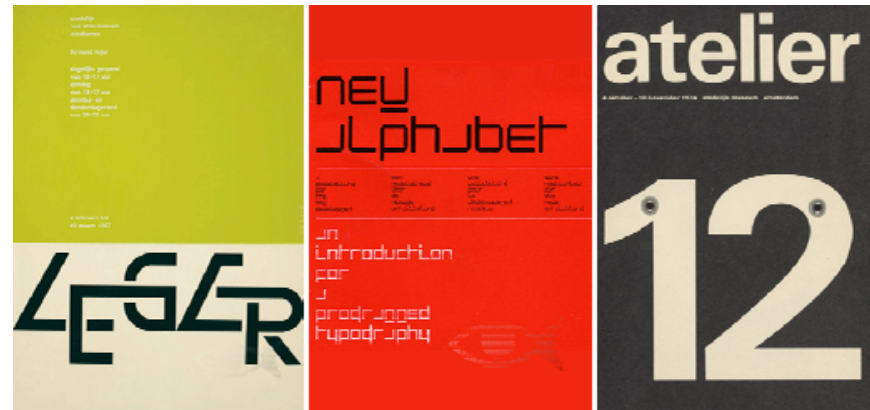

Gambar 8 Karya Wim Crouwel

(Sumber: http://images.veerle.duoh.com/uploads/design-article-images/wim-crouwel-1.png)

Lalu bagaimana dengan kubu yang membenci Helvetica? Berikut ini adalah contoh dua tokoh desainer grafis besar dunia yang tidak menyukai Helvetica. Paula Scher seorang desainer grafis yang bertempat tinggal di New York, dengan kantornya yang terkenal bernama Pentagram. Ia mengatakan bahwa sangat membenci Helvetica karena mempunyai sumbangsih terhadap tercetusnya pecah perang di Vietnam. Helvetica adalah bersifat universal dan memicu kapitalisme industri.

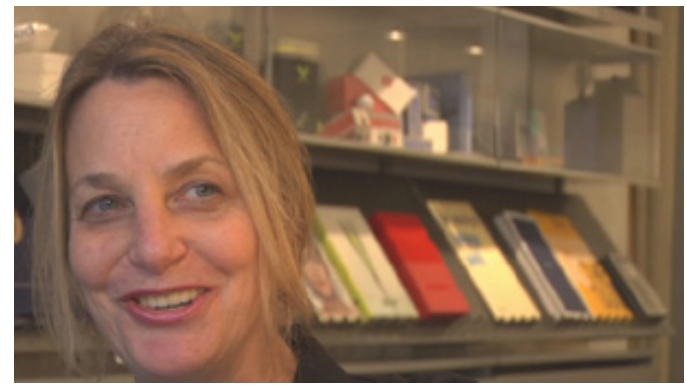

Gambar 9 Karya Paula Scher

(Sumber: http://www.helveticafilm.com/images/highres/scher.jpg) 
Berikut ini pernyataan dari Paula Scher (2007):

"The corporate culture was the visual language of big corporations, and at that time they were persuasively Helvetica. And they looked alike. They looked a little fascistic to me."

Fasisme adalah suatu paham politik yang mengutamakan atau meninggikan kekuasaan yang absolut tanpa mengutamakan prinsip demokrasi. Jadi, pernyataan Paula Scher itu jelas menolak bentuk totaliter dan ekspresi penolakan itu tertuang dalam wujudnya sebagai desainer Grafis dengan membenci Helvetica. Inilah pernyataan lanjutan dari Paula Scher (2007):

"They were clean. They reminded me of cleaning your room. I felt like it was some conspiracy of my mother's to make me keep the house clean, that all that my messy room adolescent rebellion was coming back at me in the form of Helvetica and that I had to over throw it."

Pernyataan di atas adalah sebuah perumpamaan kekuasaan yang absolut pada di sebuah keluarga. Seorang ibu mempunyai wewenang mutlak yang tidak terganggu gugat untuk dapat menguasai dan mengatur anaknya dengan memaksakan kehendak atas kamar pribadi anaknya agar terlihat bersih seusai dengan kemauannya tanpa melihat keinginan anaknya. Hal tersebut adalah analogi terhadap Helvetica dari seorang Paula Scher.

Berikut ini adalah karya besar dari desainer Paula Scher.

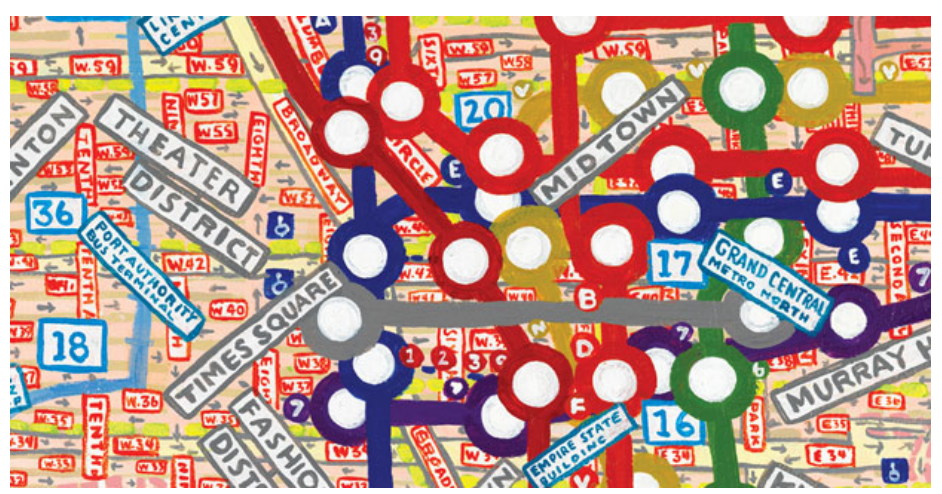

Gambar 10 Karya Peta Paula Scher

(Sumber: http://www.coolhunting.com/2011/10/31/paula-scher-maps2.jpg)

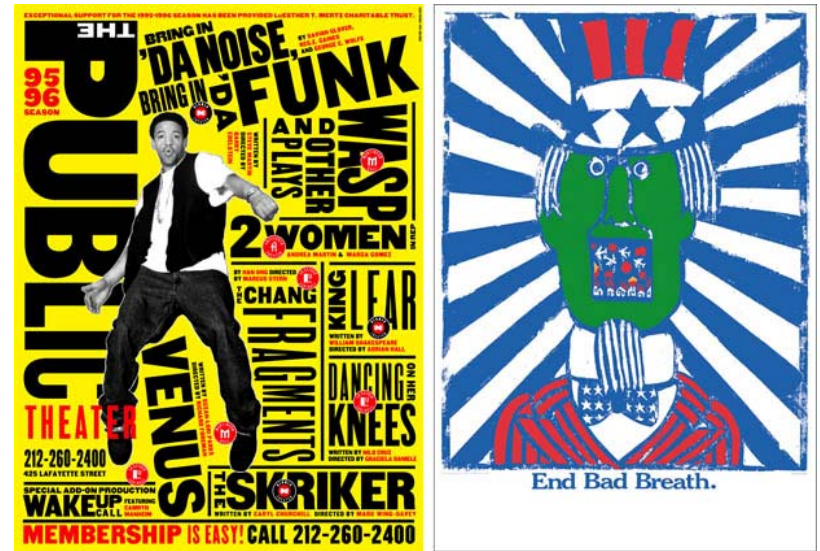

Gambar 11 Karya Paula Scher di Pentagram

(Sumber: http://new.pentagram.com/wp-content/uploads/2012/11/paula_doubleposter.jpg) 


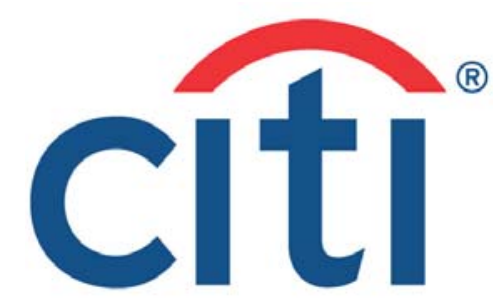

Gambar 12 Logo Citi karya Paula Scher

(Sumber: http://www.businesspundit.com/wp-content/uploads/2009/02/zzciti.jpg)

Bila melihat ketiga karya Paula Scher di atas, terlihat sekali begitu liar. Berbeda sekali dengan karya peta subway di New York, yang terlihat begitu rasional dan terukur, atau bila melihat karya Wim Crouwel yang sangat Gridnik itu. Lalu bagaimana dengan desain visual identity Citibank yang baru? Citibank adalah perusahaan korporasi besar yang sangat global dan universal. Jawabannya adalah, setidaknya Paula Scher menerima pekerjaan desain tersebut dengan tidak menggunakan font Helvetica.

Berikut ini adalah desainer bernama David Carson. Dia bertempat tinggal di Portland. Desainer Grafis ini sangat terkenal dengan prinsipnya yang unik dan sangat liar. Baginya, desain grafis tidak harus totaliter dan universal karena itu akan sangat membosankan. Dia mempelajari desain dengan cara otodidak dan menyesuaikan dengan lingkungannya, yaitu para surfer.

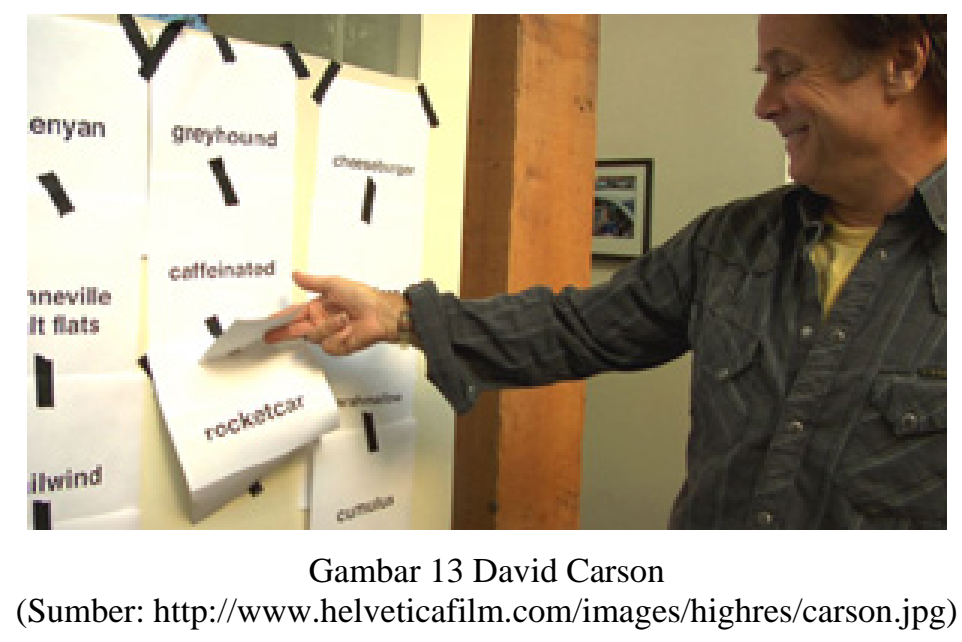

"Don't confuse legibility with communication. Just because something is legible doesn't mean it communicates and, more importantly, doesn't mean it communicates the right thing," begitulah yang diucapkan David Carson (2007). Pernyataan David Carson tersebut jelas-jelas berseberangan dengan pernyataan Wim Crouwel. Bagi David Carson, font harus mempunyai ekspresi agar memperkuat arti. Helvetica sangat tidak berekspresi karena sangat dingin dan membosankan, baginya. Sedangkan Wim Crouwel mengatakan arti sebuah kata tidak ditentukan dari bentuk desain font tersebut. Berikut ini karya dari David Carson. 


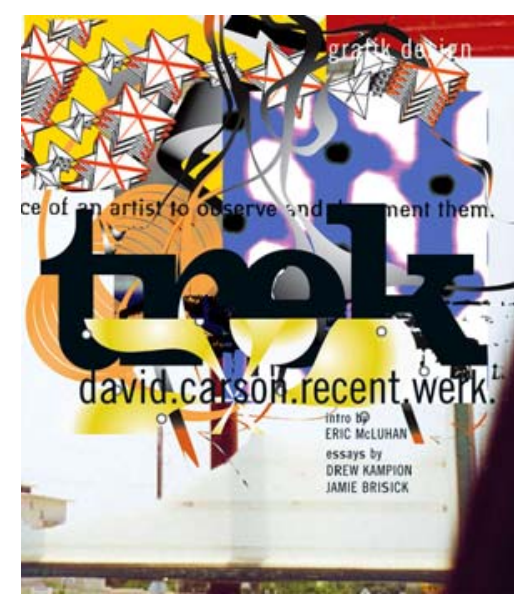

Gambar 14 Karya David Carson (Sumber: http://www.gingkopress.com/i/trek-davidcarson_ic.jpg)

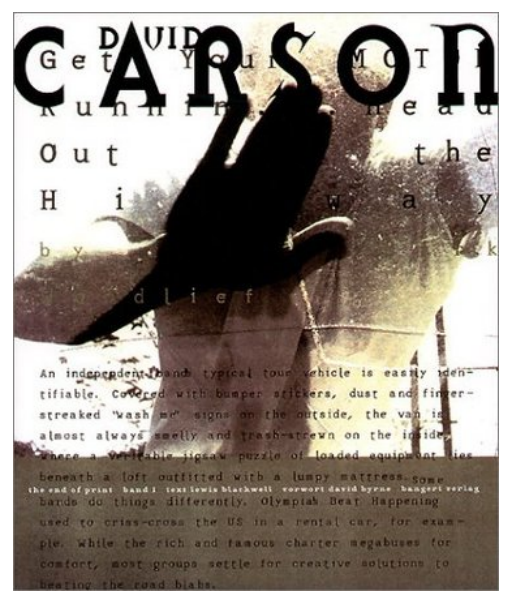

Gambar 15 Karya David Carson (Sumber:http://va312iremakdogan.files.wordpress.com /2010/12/carson_david_bw.jpg)

\section{SIMPULAN}

Berdasarkan pembahasan di atas, dapat disimpulkan bahwa tidak mungkin untuk menilai sebuah karya desain tanpa mengetahui latar belakang desainernya. Hal tersebut disebabkan latar belakang dari kedua kubu, modernisme dan postmodernisme, sangatlah bertolak belakang. Seperti yang dikatakan oleh Lyotard, bahwa semua hanyalah narasi kecil, dan tidak ada yang absolute universal.

\section{DAFTAR PUSTAKA}

Aynsley, J. (2001). A Century of Graphic Design. UK: Octopus.

Gaut, W. (2005). Filsafat Postmodernisme. Jakarta: Ledalero dan Lamalera.

Hardiman, F. B. (2011). Pemikiran Pemikiran yang Membentuk Dunia Modern. Jakarta: Erlangga.

Huswit, G. (2007). Helvetica, DVD. Swiss: Swiss Dots.

Jarret, M. S. (1997). Ray Gun: Out of Control. UK: Erlangga. 